\title{
Regeneration of Retinal Axons in the Lizard Gallotia galloti Is Not Linked to Generation of New Retinal Ganglion Cells
}

\author{
Dirk M. Lang, ${ }^{1}$ Maria del Mar Romero-Aleman, ${ }^{2}$ Juan-Francisco Arbelo-Galvan, ${ }^{2}$ \\ Claudia A.O. Stuermer, ${ }^{3}$ Maximina Monzon-Mayor ${ }^{2}$ \\ ${ }^{1}$ Department of Human Biology, Faculty of Health Sciences, University of Cape Town, \\ Observatory 7925, South Africa \\ ${ }^{2}$ Dept. de Morfologia (Biologia Celular), Facultad de Ciencias de la Salud, Universidad de Las \\ Palmas de Gran Canaria, E-35080 Las Palmas de Gran Canaria, Spain \\ ${ }^{3}$ Dept. of Biology, University of Konstanz, Universitätsstr. 10, D-78467 Konstanz, Germany
}

Received 19 October 2001; accepted 28 May 2002

\begin{abstract}
Using anterograde tracing with HRP and antibodies (ABs) against neurofilaments, we show that regrowth of retinal ganglion cell (RGC) axons in the lizard Gallotia galloti commences only 2 months after optic nerve transection (ONS) and continues over at least 9 months. This is unusually long when compared to RGC axon regeneration in fish or amphibians. Following ONS, lizard RGCs up-regulate the immediate early gene C-JUN for 9 months or longer, indicating their reactive state. In keeping with the in vivo data, axon outgrowth from lizard retinal explants is increased above control levels from 6 weeks, reaches its maximum as late as $\mathbf{3}$ months, and remains elevated for at least 1 year after ONS. By means of BrdU incorporation assays and antiproliferating cell nuclear antigen immunohisto-
\end{abstract}

\section{INTRODUCTION}

Retinal ganglion cells (RGCs) from higher and lower vertebrates exhibit remarkable differences in their reaction to optic nerve injury. While axotomy-induced

Correspondence to: D. M. Lang (dlang@cormack.uct.ac.za).

Contract grant sponsor: DFG; Contract grant sponsor: DAAD; Contract grant sponsor: DGICYT; contract grant number: PB 97/ 0434; Contract grant sponsor: Gobierno de Canarias; contract grant number: PI1999/33.

(C) 2002 Wiley Periodicals, Inc.

Published online in Wiley InterScience (www.interscience.wiley.com). DOI 10.1002/neu.10099 chemistry, we show that the late axon outgrowth is not derived from new RGCs that might have arisen in reaction to ONS: no labeled cells were detected in lizard retinas at $0.5,1,1.5,3,6$, and 12 months after ONS. Conversely, numbers of RGCs undergoing apoptosis were too low to be detectable in TUNEL assays at any time after ONS. These results demonstrate that retinal axon regeneration in $G$. galloti is due to axon regrowth from the resident population of RGCs, which remain in a reactive state over an extended time interval. Neurogenesis does not appear to be involved in RGC axon regrowth in G. galloti.

Keywords: retina; axon; regeneration; neurogenesis; reptile 
of RGCs to axon loss are preceded by up-regulation of the immediate early gene (IEG) C-JUN (Herdegen et al., 1993).

In the central nervous system (CNS) of fish and amphibians, successful regeneration of RGC axons has been shown to correlate with the absence of neurite growth inhibitory proteins (NIs) from oligodendrocytes and myelin (Lang et al., 1995; Wanner et al., 1995), which effectively block the regrowth of severed axons in the mammalian CNS by contact inhibition of growth cones (Fawcett et al., 1989; Bandtlow et al., 1990).

RGC axon regeneration through the optic nerve has also been demonstrated in three species of reptiles (Rio et al., 1989; Beazley et al., 1997; Lang et al., 1998), which occupy an intermediate position on the evolutionary scale between fish and amphibians on the one hand, and birds and mammals on the other. In the lizard Gallotia galloti, the regenerative response of RGCs after optic nerve transection (ONS) is characterized by two peculiarities: first, according to our earlier in vitro observations, outgrowth of RGC axons from lizard retinal explants following a conditioning nerve lesion sets in much later than in fish or amphibian retinal explants, where vigorous axon outgrowth occurs 1 week after optic nerve lesion (Murray, 1976; Stuermer, 1988a,b). Second, RGC axons in G. galloti were shown to regenerate in the presence of inhibitory oligodendrocytes and myelin, and NIs do not induce permanent growth cone collapse of lizard RGC axons in vitro (Lang et al., 1998). This stands in contrast to findings for most other neuronal cell types, where NIs inhibit neurite growth and induce growth cone collapse (Fawcett et al., 1989; Bandtlow et al., 1990; Bastmeyer et al., 1991; Moorman and Hume, 1993; Lang et al., 1995). However, it has also been shown that the intrinsic sensitivity of neurons to NI may depend on developmental stage: growth cones of newly generated embryonic neurons show a less dramatic response to the presence of these growth inhibitors (Bandtlow and Loschinger, 1997), and embryonic neurons, transplanted into the white matter of the adult rat spinal cord can extend processes over a long distance in this essentially inhibitory environment (Davies et al., 1994). The late onset of axon outgrowth from the retina, as well as the apparent insensitivity of regenerating retinal axons to neurite growth inhibitors in G. galloti raised the question of whether the regrowth of retinal axons observed after ONS in the lizard could in fact be due to generation of new RGCs, which, because of their immature properties, might be less sensitive to the presence of NIs and therefore would be able to extend through the heavily myelinated optic nerve and tract.
In the present study we first established the in vivo time course of RGC axon regrowth after ONS in the lizard G. galloti by anterograde horseradish peroxidase (HRP) tracing and immunostaining with antibodies against neurofilaments. To determine whether regrowing lizard retinal axons are derived from the resident RGC population or perhaps from newly generated RGCs, we monitored the proliferative response of retinal cells to ONS in bromodeoxyuridine (BrdU) incorporation assays and with antibodies against the proliferating cell nuclear antigen (PCNA). We also used antibodies to the IEG C-Jun to determine the reactive state of the axotomized lizard RGCs, as has been done previously in mammals and fish (Herdegen et al., 1993). Because apoptotic cell death of RGCs as a consequence of ONS ultimately causes the loss of almost the entire RGC population in the mammalian retina, but plays a relatively minor role in fish and amphibians, we also analyzed the occurrence of apoptosis among retinal cells in reaction to ONS in $G$. galloti.

\section{MATERIALS AND METHODS}

\section{Animals}

Adult Canary Lizards ( $G$. galloti) were collected on the island of Tenerife under license and in compliance with local environmental and animal welfare legislation. The animals were kept in large holding tanks fitted with heaters and overhead lighting, and fed on a mixed diet of commercially available cat food as well as a variety of live insects and fruit.

\section{Optic Nerve Transection}

The lizards were anesthetized on ice. An incision was made along the margin of the largest supraocular osteodermal plaque, to expose the optic nerve. The nerve was transected about $1 \mathrm{~mm}$ from the eye using iridectomy scissors, and care was taken not to injure the blood vessels supplying the retina. A strand of the nerve sheath was left intact to insure direct apposition of the cut nerve ends. Following optic nerve transection, the osteodermal plaque was put back in place and the lizards were returned to their holding tanks. Recovery was rapid, and the animals behaved normally after unilateral ONSs. The lizards were left to recover for up to 12 months after surgery. At least three animals were examined for the different experiments at individual time points following ONS. In a few animals, the cut nerve ends failed to remain closely opposed to each other. Here, continuity of the optic nerve was not restored, and no axon regeneration was observed. These animals were not included in the analysis. 


\section{HRP Tracing Experiments}

For anterograde tracing of regenerating retinal axons, $1 \mu \mathrm{L}$ of a $10 \%(w / v)$ solution of HRP (type VI; Sigma, Deisenhofen, Germany) in PBS containing 1\% Triton X-100 was injected into the right eye of cold-anesthetized lizards at various time points after ONS, as well as into eyes of control animals that had not undergone ONSs. For each time point after operation, at least three animals were injected and analyzed. Following the HRP injections, animals were allowed to recover for 4 days, after which time the brains were dissected and processed for HRP histochemistry.

\section{BrdU Injections}

To label cell nuclei undergoing DNA replication, coldanesthetized lizards at various time points after ONS were injected intraperitoneally with $10 \mu \mathrm{L}$ of a $100 \mathrm{~m} M$ solution of the synthetic thymidine analog BrdU (Sigma) in PBS. After daily injections over a period of 2 weeks, the brains and retinas were dissected free and processed for immunohistochemical detection of the incorporated BrdU.

\section{Retinal Explant Culture}

Explants of adult lizard retina were prepared as described previously for goldfish (Bastmeyer et al., 1991; Lang et al., 1995; Wanner et al., 1995) at defined time points after ONS. Briefly, the retinas were dissected free from the sclera, and flat-mounted with the ganglion cell layer up on Hybond $\mathrm{N}$ membranes (Amersham Buchler, Braunschweig, Germany). The retinas were then cut into strips (400 $\mu \mathrm{m}$ wide) on a Mcllwain tissue chopper and placed, with the RGC layer facing the substrate, on glass coverslips coated with polylysine and laminin (Becton-Dickinson, Heidelberg, Germany). The retina strips were held in place by stainless steel bars. Retinal explants were cultured for 3 days at $28^{\circ} \mathrm{C}$ in modified L15 culture medium (Mains and Patterson, 1973), supplemented with $5 \% \mathrm{FCS}$, in the presence of $5 \% \mathrm{CO}_{2}$.

\section{Histochemical Procedures}

For the detection of HRP in anterograde tracing experiments, lizards were perfused and the brains postfixed with phosphate buffer containing $4 \%$ paraformaldehyde and $0.2 \%$ glutaraldehyde, $\mathrm{pH}$ 7.4. After cryoprotection and sectioning (20 $\mu \mathrm{m}$ thick), HRP histochemistry was performed according to established procedures using diaminobenzidine (DAB) as a chromogenic substrate and nickel chloride to intensify staining. After thorough washing with phosphate buffer, the stained sections were coverslipped with Entellan (Merck, Darmstadt, Germany).

To visualize axons extending from retinal explants, cultures were briefly rinsed with L15 medium, fixed, and permeabilized by immersion in methanol $\left(5 \mathrm{~min},-20^{\circ} \mathrm{C}\right)$ and $4 \%$ paraformaldehyde in PBS (5 min, RT). After three washes in PBS (5 min each), the cultures were incubated with a monoclonal antineurofilament antibody (SMI-31;
Sternberger Monoclonals Inc., Lutherville, USA) diluted in blocking solution $\left(2 \mathrm{~h}, 37^{\circ} \mathrm{C}\right)$. Following three more washes with PBS, bound primary antibodies were visualized by incubation with donkey-antimouse-Cy-3 (Dianova, Hamburg, Germany) for $1 \mathrm{~h}$ at $37^{\circ} \mathrm{C}$. Cultures were coverslipped in Mowiol (Hoechst, Frankfurt, Germany) after three more washes in PBS. In order to stain retinal axons, glial cells at the lesion site, or the IEG C-JUN in the lizard retina, cryosections (10 $\mu \mathrm{m}$ thick) of unfixed CNS tissue were cut and, after immersion in methanol, immunolabeled according to the same procedure as retinal explants, using antineurofilament monoclonal antibodies, monoclonals to glial fibrillary acidic protein (GFAP; clone G-A-5; Sigma), and either rabbit antiserum to fibronectin (BioTrend, Cologne, Germany) or rabbit polyclonal antibodies to C-JUN (kind gift of T. Herdegen, Kiel, Germany), respectively. Bound primary antibodies were visualized using the appropriate secondary antibodies (donkey-antimouse-Cy-3 or goat antimouse-DTAF, and donkey-antirabbit-Cy-3 or goat-antirabbit-DTAF; all from Dianova), and cell nuclei were counterstained with 4',6'-diamidino-2-phenylindole hydrochloride (DAPI; $0.5 \mu \mathrm{g} / \mathrm{mL}$ in PBS; Sigma).

To detect incorporated BrdU in cryosections of lizard CNS tissue, animals were perfused with $4 \%$ paraformaldehyde in phosphate buffer, $\mathrm{pH} 7.4$, and the brains dissected out and postfixed overnight. Following cryoprotection in phosphate buffer containing 30\% sucrose (overnight at $4{ }^{\circ} \mathrm{C}$ ), the brains were sectioned and subjected to immunohistochemistry. The sections were immersed into methanol $\left(5 \mathrm{~min},-20^{\circ} \mathrm{C}\right)$ and washed three times in PBS (5 min each wash). To denature double-stranded DNA, the sections were immersed into $1 \mathrm{~N} \mathrm{HCl}$ for $1 \mathrm{~h}$ and washed thoroughly in PBS (at least $5 \times 5 \mathrm{~min}$ ) prior to incubation with monoclonal anti-BrdU antibodies (Becton-Dickinson) in blocking solution (PBS containing $1 \%$ BSA and $0.02 \%$ thimerosal as a preservative) for $2 \mathrm{~h}$ at $37^{\circ} \mathrm{C}$. Following three washes in PBS, secondary antibodies (donkey-antimouse-Cy-3) were incubated with the sections in blocking solution $(1 \mathrm{~h}$ at $37^{\circ} \mathrm{C}$ ). After another three washes in PBS, sections were coverslipped in Mowiol containing n-propylgallate as antifading agent.

Anti-BrdU immunohistochemistry was also performed in retina wholemount preparations. During dissection, special care was taken to leave the retinal margin, an area of continuous neurogenesis in fish and amphibians, intact. Retinas were flat-mounted on Hybond $\mathrm{N}$ membranes (Amersham Buchler), fixed overnight in $4 \%$ paraformaldehyde in PBS, and permeabilized by immersion into methanol (10 $\min ,-20^{\circ} \mathrm{C}$ ). Following three washes with PBS (10 min each wash), the retinas were transferred to $1 \mathrm{~N} \mathrm{HCl}$ for $1 \mathrm{~h}$, washed extensively $(5 \times 10 \mathrm{~min})$, and incubated with monoclonal anti-BrdU in blocking solution overnight at $4^{\circ} \mathrm{C}$. Following extensive washes with PBS, the retinas were incubated with secondary antibody $\left(2 \mathrm{~h}, 37^{\circ} \mathrm{C}\right)$, washed, and coverslipped in Mowiol.

Detection of PCNA was performed immunohistochemically on paraffin sections. Lizards were perfused and the dissected brains and retinas postfixed with Bouin's fixative. 
The tissue was processed according to established procedures, subjected to a heat denaturing step $\left(10 \mathrm{~min}, 100^{\circ} \mathrm{C}\right.$ in citrate buffer, $\mathrm{pH}$ 6.0), and incubated with a mouse monoclonal to PCNA (Novocastra, Newcastle, Great Britain) overnight at $4^{\circ} \mathrm{C}$. After repeated washing, bound primary antibodies were detected with HRP-conjugated goat-antimouse antibodies. Staining was visualized using DAB as a substrate, with or without nickel intensification. In some experiments, sections were counterstained with neurofilament-specific $\mathrm{ABs}$ to visualize axons.

Detection of apoptotic cell death was performed according to the TUNEL method. The Apoptag Kit (Oncor Appligene, Illkirch, France) was used on retina cryosections and wholemount preparations according to the manufacturer's instructions. For positive controls, apoptosis of RGCs was induced by injection of $0.5 \mu \mathrm{L}$ of $1 M$ sodium glutamate into the vitreous.

\section{RESULTS}

\section{Retinal Axon Regeneration In Vivo}

To determine the time course of RGC axon regrowth, we performed anterograde HRP tracing as well as antineurofilament immunohistochemistry in the visual system of $G$. galloti at various time points $(0.5,1,2$, 3, 6, 9, and 12 months) after ONS. Antibodies to fibronectin and GFAP were used to visualize postlesion changes of the optic nerve tissue adjacent to the transection site.

By 2 months after ONS, antineurofilament-positive retinal axons are starting to cross the lesion site [Fig. 1(a)], which is at this stage characterized by the absence of GFAP-positive glial cells [Fig. 1(b)], but shows high levels of fibronectin immunoreactivity [Fig. 1(c)]. At that time, regrowing axons have not yet arrived at the optic chiasm, judged by the absence of antineurofilament staining on the regenerating side [Fig. 2(a,b)]. Three months after ONS, HRP tracing reveals bundles of regrowing retinal axons in the optic tract [Fig. 3(a)], en route to the optic tectum. At 6 months after ONS, antineurofilament immunostaining reveals large numbers of retinal axons traversing the transection site [Fig. 1(e)], where at this stage strongly GFAP-immunoreactive glial cells predominate [Fig. 1(f)] while antifibronectin immunoreactivity has decreased [Fig. 1(g)]. Thus, a glial scar resembling those seen in injured mammalian optic nerves (Fawcett and Asher, 1999) develops in the lizard, but seemingly does not pose much of an obstacle to the regenerating RGC axons.

Throughout the entire depth of the optic tract regenerating axons are now seen, characterized by their strongly fasciculated growth pattern [Fig. 2(c)]. This pattern is also prominent in the HRP tracing experiments at that stage of axon regeneration (data not shown). Nine months after ONS, HRP tracing reveals a further increase in numbers of regrowing axons in the optic chiasma and tract [Fig. 3(b,d)]. By now, the regenerated axons have arrived in the optic tectum [Fig. 3(f, $\left.\mathrm{f}^{\prime}\right)$ ]. At later stages up to 1 year after ONS, no major changes compared to the pattern at 9 months after ONS were observed (data not shown). Interestingly, there are large numbers of regenerating retinal axons growing along aberrant pathways. While HRP tracing in control animals shows an almost complete separation of axons in the ipsi- and contralateral optic tract [Fig. 3(e)], and virtually all axons cross over contralaterally at the optic chiasm [Fig. 3(c)], numerous axons are actually seen remaining ipsilaterally in lizards after ONS [Fig. 3(b,d)]. This aberrant growth of retinal axons occurs early during optic nerve regeneration (data not shown), but is particularly evident at later stages [Fig. 3(b,d)]. Moreover, in the optic tectum, the pattern established by the regenerated axons [Fig. 3(f)] appears disorderly in comparison with that in intact lizards [Fig. 3(g)]. Most strikingly, aberrant retinal axons enter the contralateral, intact optic nerve [Fig. 3(h)], something we never observed in the control animals.

These results show that axotomized RGCs in $G$. galloti can regrow their axons across the lesion site back to their target area. However, axon regeneration follows a very slow time course. Moreover, a high proportion of regenerating axons grow along aberrant pathways-even into intact myelinated CNS areas.

The IEG C-JUN is considered a marker for the reactive state of RGCs following axotomy (Herdegen et al., 1993). In light of the unusual time course of retinal axon regrowth in G. galloti, we determined the duration of C-JUN expression by RGCs after ONS using anti-C-JUN antibodies. We found C-JUN to be up-regulated by lizard RGCs up to at least 9 months after ONS [Fig. 4(c)], concomitant with an enlargement of RGC nuclei [Fig. $4\left(\mathrm{~b}^{\prime}, \mathrm{d}^{\prime}\right)$ ], which reflects the prolonged time course of retinal axon regrowth. However, C-JUN was up-regulated as early as 1 week after ONS (data not shown), which stands in contrast to our finding that regrowth of RGC axons across the lesion site does not commence before 2 months after ONS.

\section{Retinal Axon Outgrowth In Vitro}

The unusual, delayed time course of retinal axon regeneration in vivo, together with the finding that C-JUN is up-regulated before the actual onset of axon regeneration, might be due to an inhibition of axon regrowth by unfavorable substrate properties of the 

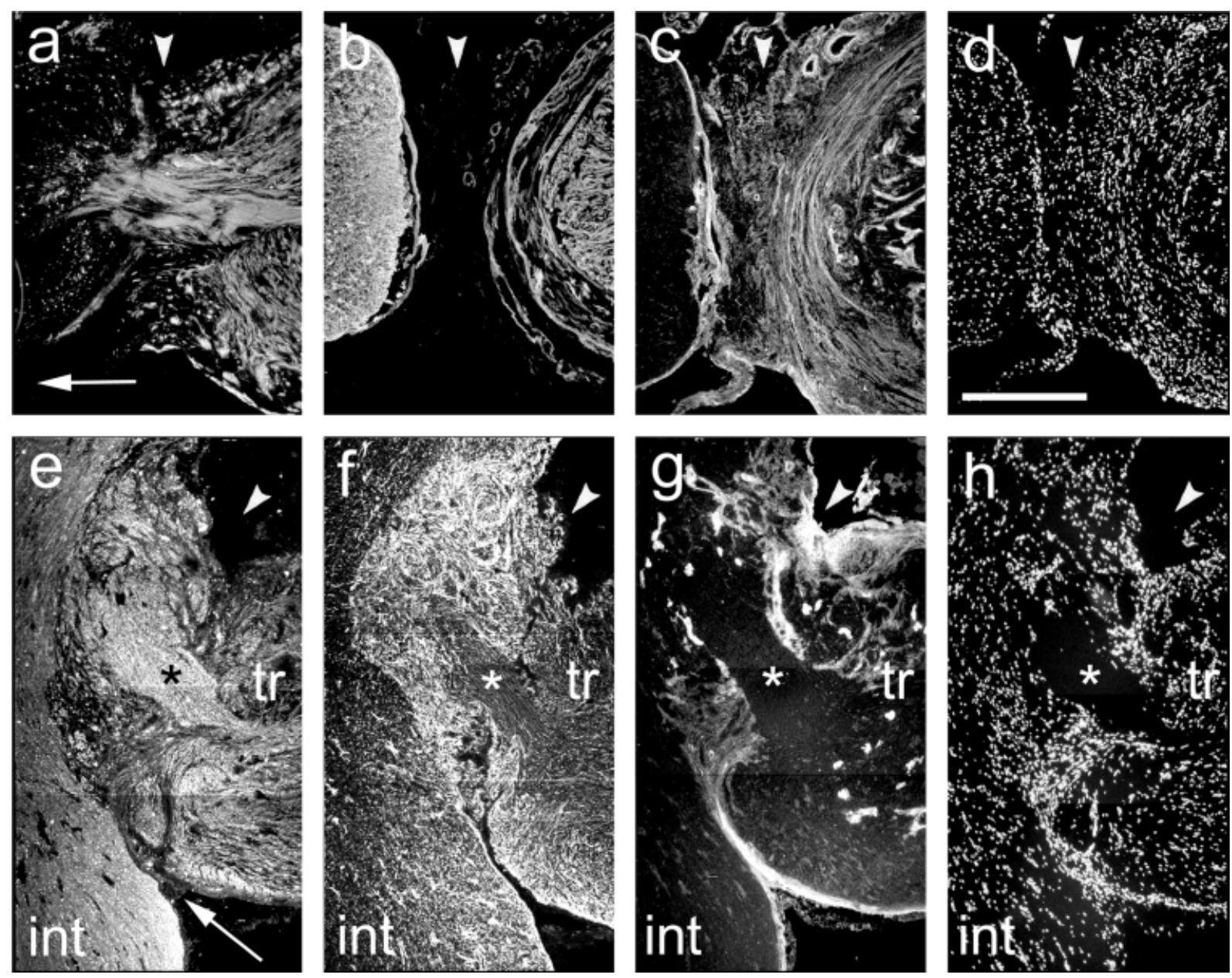

Figure 1 Fluorescence micrographs of consecutive longitudinal sections (10 $\mu \mathrm{m}$ thick) of the transected optic nerve of Gallotia galloti 2 months (a-d) and 6 months after transection $(\mathrm{e}-\mathrm{h})$. The transection site is indicated by arrowheads. Arrows in (a) and (e) indicate direction of retinal axons regrowing towards the brain. Sections $(\mathrm{e}-\mathrm{h})$ were taken near the optic chiasma; adjacent to the transected optic nerve (tr), the intact nerve (int) is visible. Two months after ONS, antineurofilament-immunoreactive retinal axons are beginning to traverse the lesion site (a). At this stage, cells at the lesion site are GFAP-negative (b) and fibronectin-positive (c). The presence of cell bodies at the lesion site is indicated by DAPI-staining (d). Six months after ONS, neurofilament-positive RGC axons cross the lesion site in thick bundles [(e), position marked by asterisk]. Except for the area occupied by axon bundles (marked by asterisk), the lesion site now shows high levels of GFAP immunoreactivity (f), while fibronectin immunoreactivity has decreased (g). Absence of DAPIlabeling (h) shows that some of the axon bundles crossing the lesion site do not contain any glial cell bodies (marked by asterisk). Scale bar: $200 \mu \mathrm{m}$.

microenvironment within the visual pathway. We therefore cultured lizard retinal explants, derived from animals at various time points after ONS, on laminin, a substrate that favors growth of RGC axons (Smalheiser et al., 1984), and compared axon outgrowth from the explants after 3 days in culture. In keeping with our findings in vivo, very few axons grew out of explants from retinas up to 6 weeks after ONS [Fig. 5 (b)], with only a slight increase in numbers up to 2 months. By 3 months after ONS, however, retinal explants showed massive axon outgrowth [Fig. 5(a)], which only slowly diminished with longer time intervals after ONS. Axon outgrowth from retinal explants, 1 year after ONS, was still above the outgrowth levels observed in explants from control animals (not shown).

These results show that the delayed time course of retinal axon regeneration in G. galloti is not caused by 

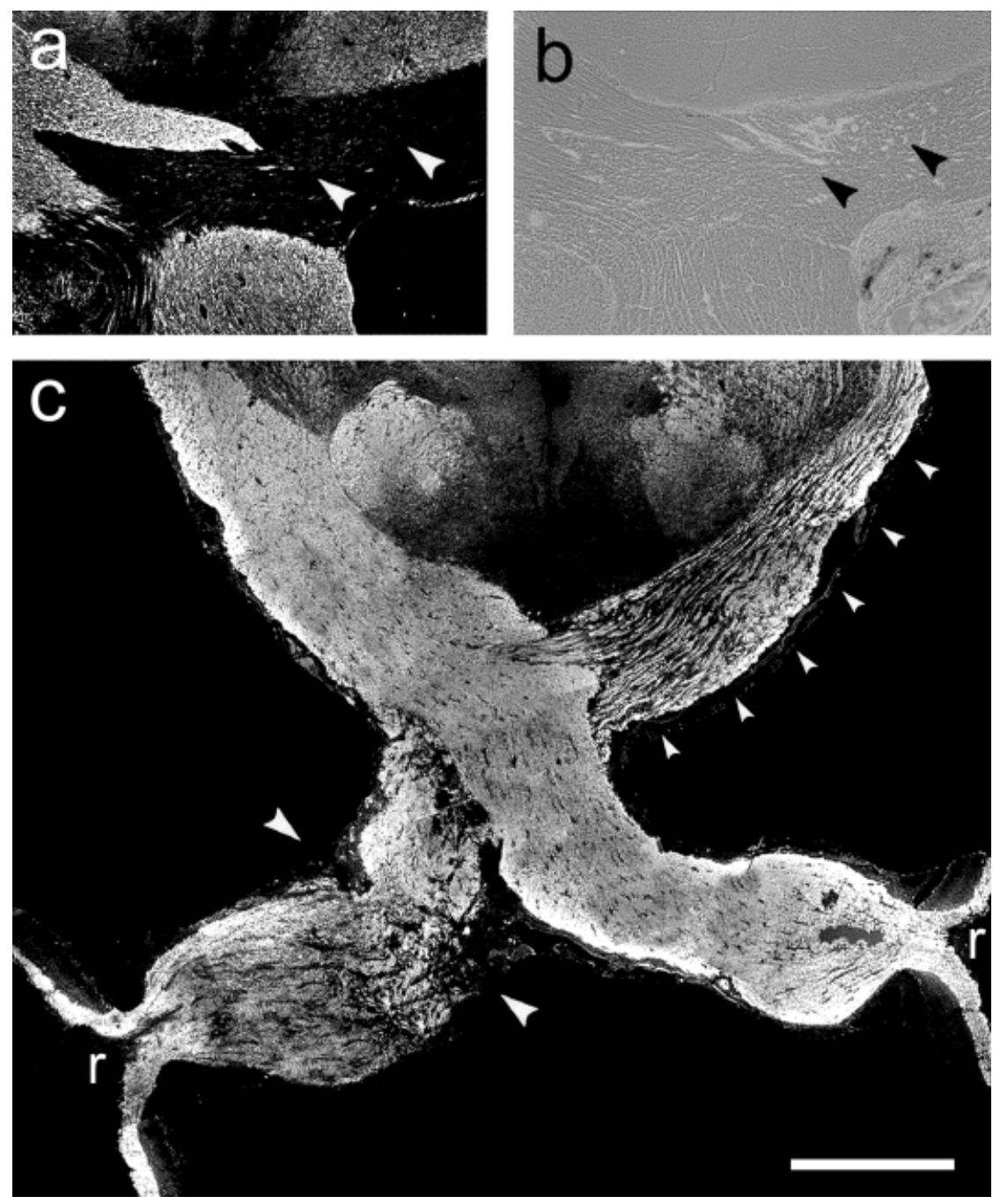

Figure 2 Fluorescence micrographs of neurofilament immunoreactivity in horizontal sections of the optic nerves, chiasma, and optic tracts after unilateral optic nerve transection. Two months postlesion (a), hardly any regrowing axons are detectable in the regenerating portion of the optic chiasm (indicated by arrowheads). (b) Phase contrast image of (a). Six months after ONS (c), numerous bundles of regenerating axons are seen in both deep and superficial layers of the optic tract (marked by small arrowheads). Transection site is indicated by large arrowheads. r, retina. Scale bar: $800 \mu \mathrm{m}$.

unfavorable substrate properties of the microenvironment. Rather, the cause(s) for this unusual time course must be found in the retina itself.

\section{Proliferative Response of Retinal Cells after Axotomy}

A possible mechanism for the late onset of retinal axon regeneration in G. galloti might be based on the generation of new RGCs as a reaction to ONS, which would subsequently send their axons through the transected optic nerve. To detect intraretinal cell pro- liferation, we injected lizards from the time of ONS, 2 and 6 weeks, as well as 3,6, and 12 months after ONS over 2 weeks intraperitoneally with $\mathrm{BrdU}$, a thymidine analog that becomes incorporated into the DNA during the replication cycle. Moreover, we tested for the expression of PCNA, a protein considered a marker for proliferating cells in the lizard brain (Margotta et al., 1999). As early as 6 weeks after ONS, and at all other stages examined thereafter, a large number of BrdU-labeled cell nuclei were detected in the transected optic nerve, particularly around the lesion site [Fig. 6(c,d); 6 months after 

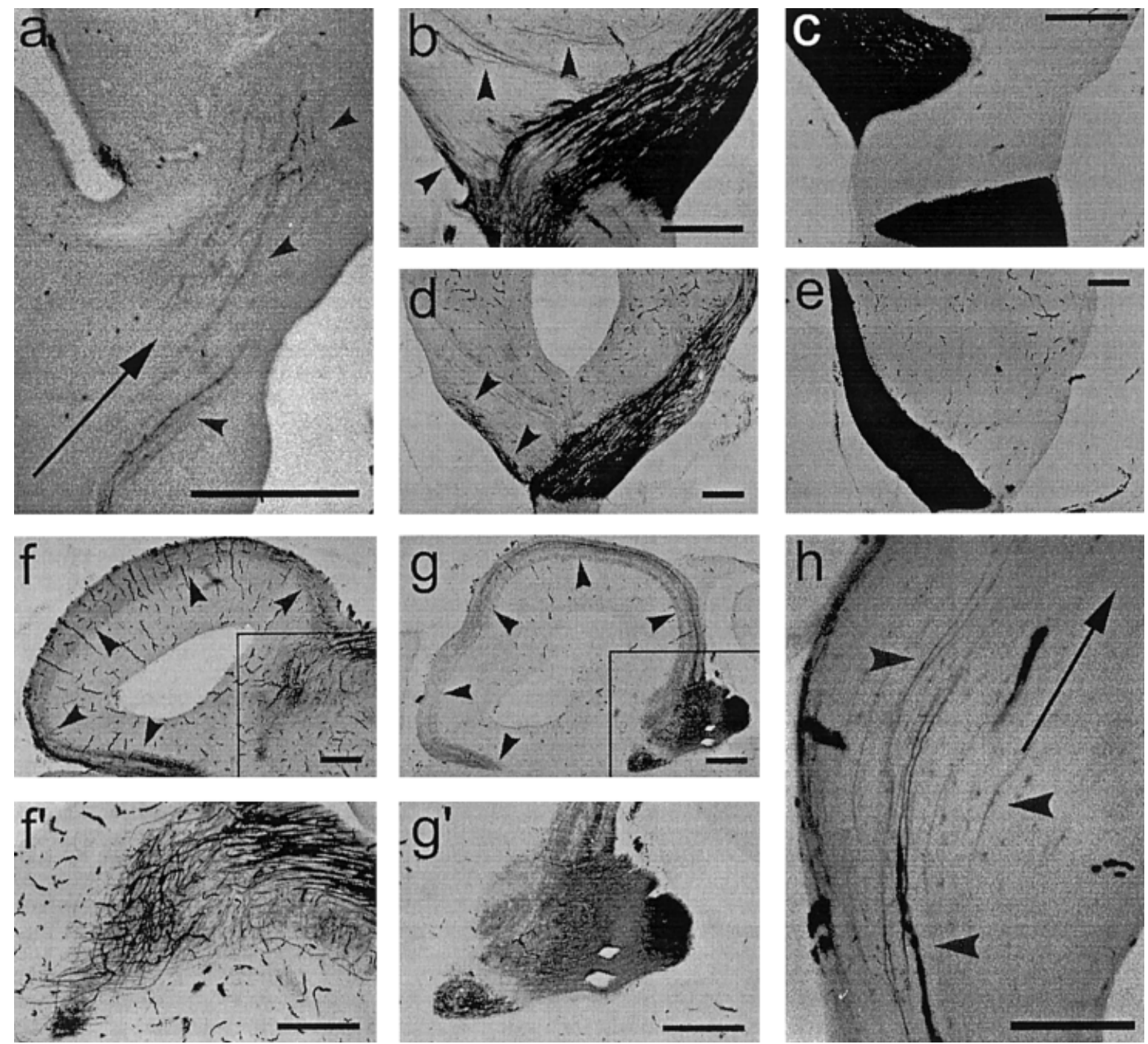

Figure 3 HRP-tracing of regenerating lizard retinal axons. (a) Horizontal section of the optic tract near the chiasma. Single HRP-filled growth cones in the regenerating optic tract 3 months after ONS demonstrate late onset of retinal axon regeneration. Arrowheads indicate positions of labeled axons; arrow denotes direction of axon growth. (b-e) Horizontal sections through the optic chiasma (b,c) and optic tract (d,e) 9 months after ONS (b,d) and in an unlesioned animal (c,e). At this stage, large numbers of axons have regenerated through the chiasma (b) and optic tract (d), but numerous aberrant HRP-labeled axons are seen entering the ipsilateral side (indicated by arrowheads) at the level of the chiasma and tract. Ipsilaterally running axons are virtually absent in the corresponding sections from an unlesioned animal (c,e). Horizontal sections of the optic tectum of lizards 9 months after ONS (f) reveal that retinal axons have regrown into the optic tectum, but lack the layered and orderly arrangement seen in corresponding sections of unlesioned control specimens [ $(\mathrm{g})$; presence of labeled RGC axons in the tecta indicated by arrowheads]. This difference is particularly evident at the entry point of the retinal axons into the optic tectum $\left[\left(\mathrm{f}^{\prime}, \mathrm{g}^{\prime}\right)\right.$, higher magnification subfields. Positions indicated by boxes in $(\mathrm{f}, \mathrm{g})]$. Misrouted axons are also frequently seen in longitudinal sections of the contralateral, intact optic nerve [(h), indicated by arrowheads. Arrow points towards the retina]. Scale bars: $500 \mu \mathrm{m}$.

nerve lesion]. However, no BrdU-labeled cells were seen in the retina at any time during the analyzed interval between 2 weeks and 1 year after ONS [Fig. 6(b,e) show portions of a retina 6 weeks after lesion; Fig. 6(c), 6 months after lesion]. The only site within the eye where BrdU-labeled cells occurred was in the 

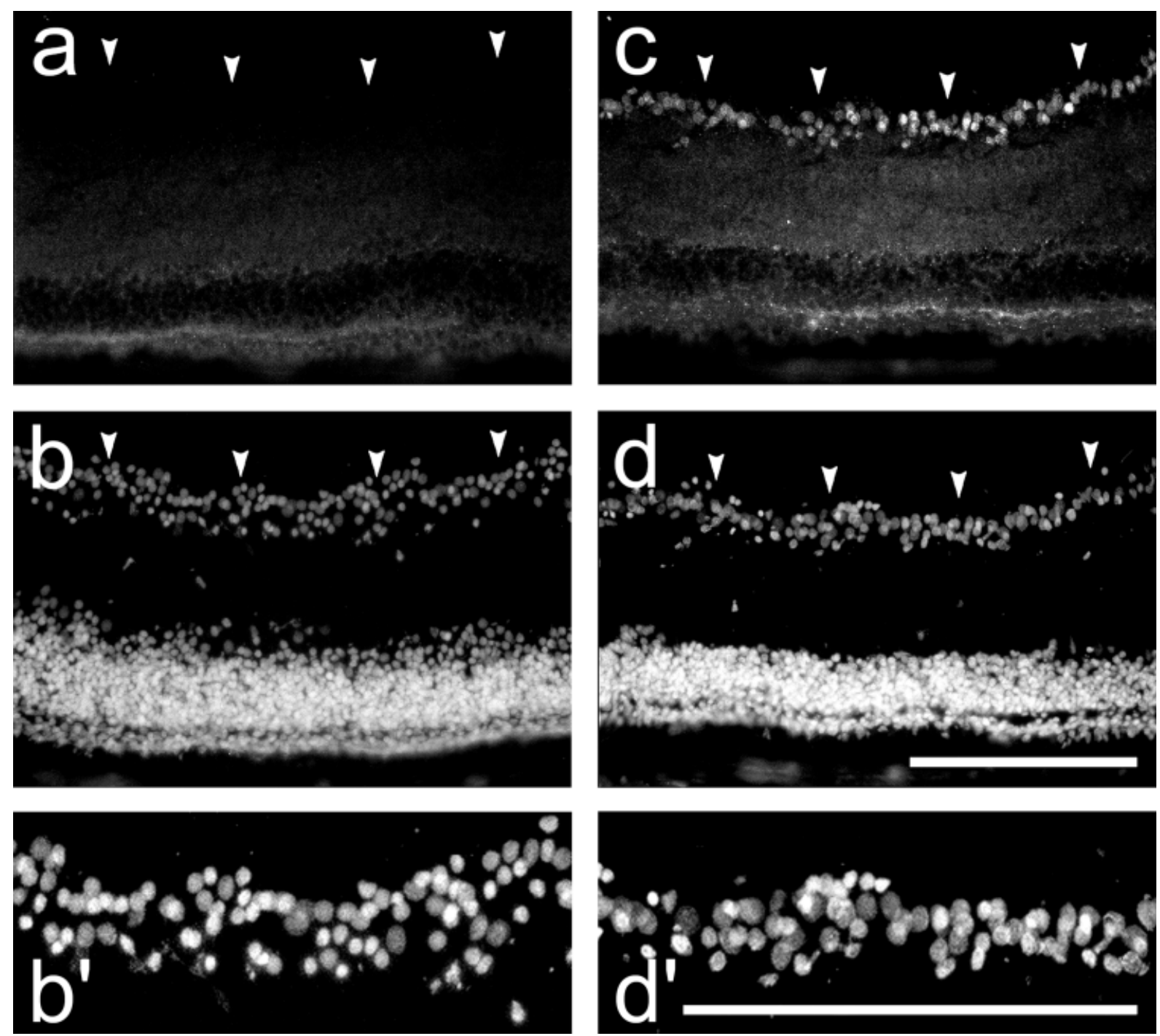

Figure 4 Fluorescence micrographs of C-Jun expression in normal (a,b, $\left.\mathrm{b}^{\prime}\right)$ and regenerating lizard RGCs (c,d,d'). In sections of a control retina, RGCs are not stained with antibodies to C-Jun (a). In contrast, RGCs in a retina 9 months after ONS are C-Jun positive (c). Positions of RGCs are indicated by arrowheads and by counterstaining with DAPI $(b, d) .\left(b^{\prime}, d^{\prime}\right)$ Higher magnification subfields of (b,d). RGC nuclei still appear enlarged 9 months after ONS (d') compared to those in sections from a nonlesioned control animal ( $\left.b^{\prime}\right)$. Scale bar: $200 \mu \mathrm{m}$.

conus papillaris, a cone-shaped structure protruding into the vitreous from the optic disc [Fig. 6(a,b,e)]. BrdU incorporation in the lesioned optic nerve as well as in the conus papillaris was clearly linked to optic nerve injury, as no BrdU-labeled cells were detectable in the intact optic nerve, and much lower numbers occurred in the conus papillaris of unlesioned control animals [Fig. 6(a)]. It is noteworthy that in G. galloti no BrdU-labeled cells were ever seen at the retinal margin, either in control animals or after ONS [Fig. $6(\mathrm{e})]$. This contrasts with the situation in fish and amphibians-in these animals the outer margin of the retina is a proliferative center, where young RGCs are generated lifelong (Johns et al., 1978; Stuermer and Bastmeyer, 2000). These results were confirmed by our analysis of PCNA expression after ONS (Fig. 7). Thus, in G. galloti, no proliferation of RGCs occurs as a reaction to ONS, and generation of new RGCs cannot account for the regenerative response of retinal axons in these lizards.

\section{Axotomy-Induced Apoptosis of Retinal Cells}

The results described so far lead to the conclusion that retinal axon regeneration in $G$. galloti is affected by 

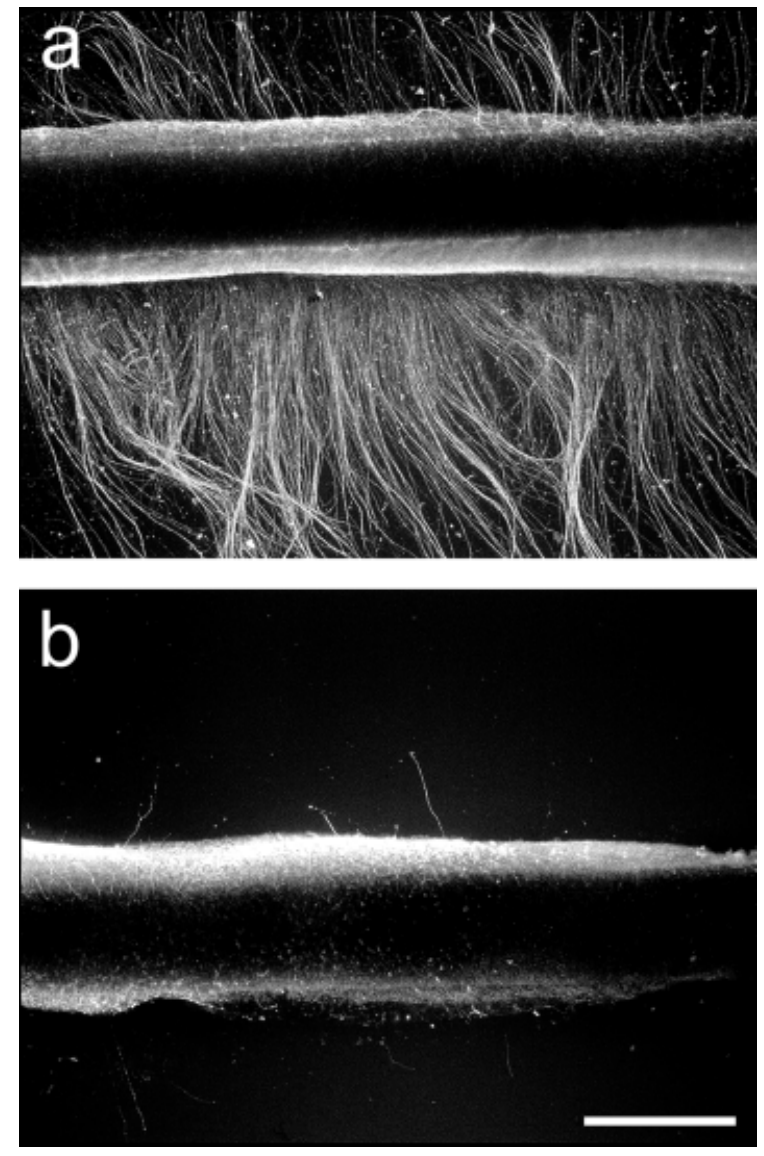

Figure 5 In vitro regeneration of lizard retinal axons. Retinal explants prepared 3 months after ONS and labeled by antineurofilament immunofluorescence show strong axon outgrowth on laminin (a). Explants from control retinas (b) and up to 6 weeks after ONS show only sparse axon outgrowth. Scale bar: $400 \mu \mathrm{m}$.

the resident RGC population. The late onset and prolonged time course of axon regrowth consequently means that RGCs have no target contact over a long period of time; however, axotomy and loss of contact with the target are known to cause apoptotic cell death in many neurons, including mammalian RGCs (Bahr, 2000). Therefore, we tested for the occurrence of apoptosis in the lizard retina at various time points after ONS, using the TUNEL method. We analyzed retinas and optic nerves at $0.5,1.5,6$, and 12 months after ONS. At no time point during this interval were any TUNEL-labeled cells seen in the retina [Fig. 8(a), 6 weeks after nerve lesion; Fig. 8(c), 6 months after nerve lesion]. Strikingly, however, TUNEL-labeled cells were found in the conus papillaris [Fig. 8(a)] and in the vicinity of the lesion site in the optic nerve (not shown), particularly in the earlier stages of regeneration and up to 6 months after ONS. This distribution of TUNEL-labeled cells closely resembles that of the BrdU-labeled proliferating cells, indicating that apoptosis in these areas might be a secondary event resulting from reactive cell proliferation as a consequence of ONS. These results demonstrate that, in contrast to the situation in mammals, RGCs in $G$. galloti are apparently not undergoing apoptosis after axotomy. However, apoptotic cell death can be induced in lizard RGCs by microinjection of sodium glutamate into the vitreous [Fig. 8(e,f)], indicating that these cells have the intrinsic capability for undergoing apoptosis, but appear to be prevented or protected from doing so after optic nerve lesion.

\section{DISCUSSION}

This study demonstrates that RGCs in the lizard $G$. galloti are capable of axon regeneration. Moreover, it shows that axon regrowth in G. galloti occurs over an unusually prolonged time course, when compared to other systems where axon regeneration is successful, such as the fish (Murray, 1976) and amphibian visual systems (Humphrey, 1988). This unusual time course, however, does not appear to be a hallmark of RGC axon regeneration in reptiles in general (Dunlop et al., 2000). The regeneration process in G. galloti is accompanied by numerous pathfinding errors of the regrowing axons. Using BrdU incorporation assays as well as antibodies against PCNA, we were able to show that this delayed regenerative response is not based on the proliferation of retinal cells in reaction to ONS, but on true axon regeneration by the resident population of RGCs. In addition, up-regulation of the IEG C-JUN in RGCs over at least 9 months following ONS shows that individual RGCs maintain their reactive state throughout the time interval in which axon regeneration is observed.

The only proliferative center we observed within the eye is the conus papillaris, a richly vascularized structure homologous to the pecten oculi of the avian eye (Dieterich and Dieterich, 1975). Given its structure and cell composition (Braekevelt, 1989), as well as the fact that no BrdU-labeled cells were seen immigrating from the conus papillaris into the retina, it appears highly unlikely that any new neurons are generated there or that this constitutes the source of regrowing axons. At this stage, however, we do not know the significance of the increased rate of cell proliferation in the conus papillaris in response to ONS.

Our results regarding the absence of formation of new RGCs in the retina of adult G. galloti are in agreement with those obtained by Beazley et al. (1998) using ${ }^{3} \mathrm{H}$-thymidine incorporation in the ornate 

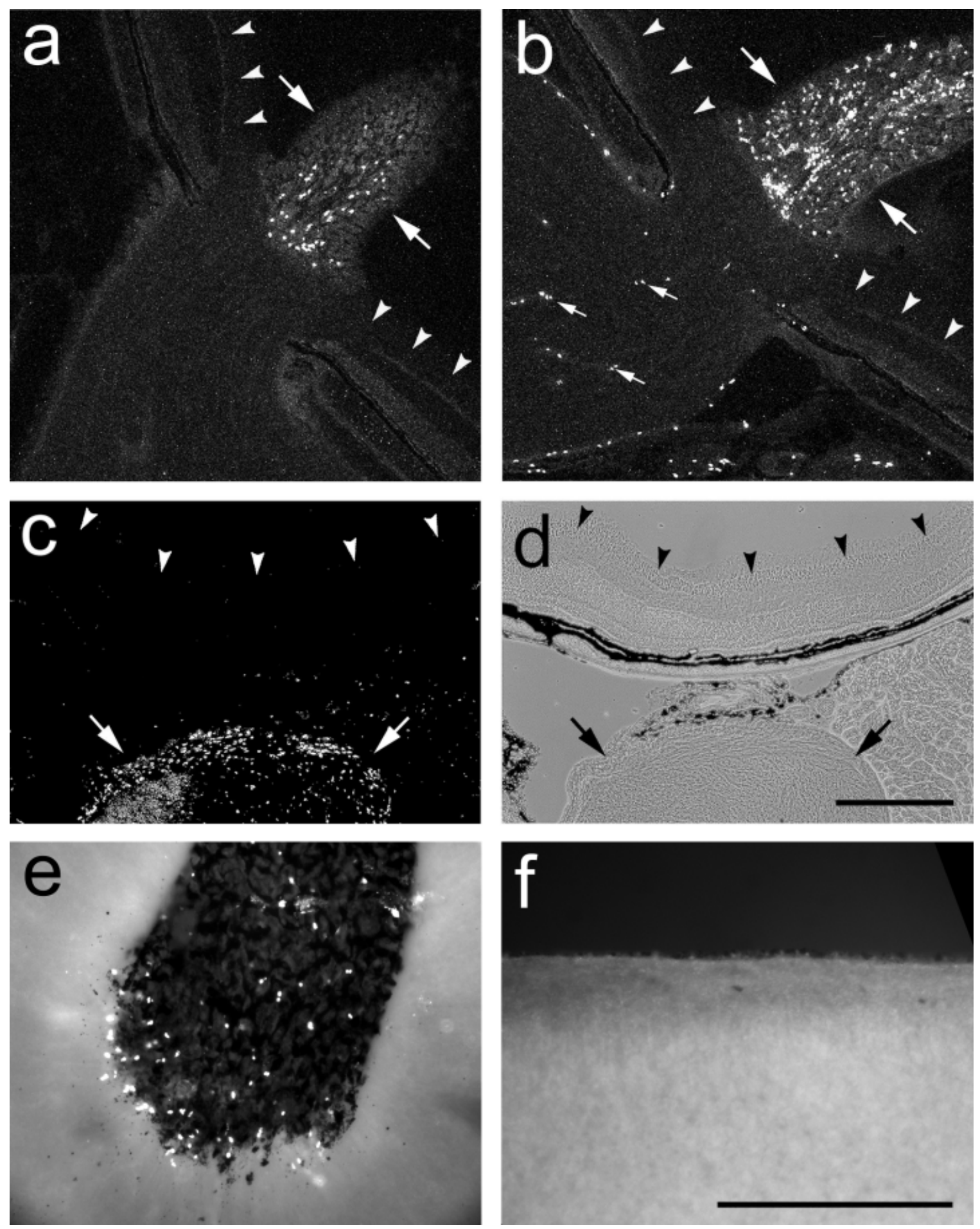

Figure 6 Fluorescence micrographs of BrdU labeling in the lizard retina and optic nerve. In cross-sections of the control retina (a) as well as 6 weeks (b) and 6 months after optic nerve transection (c), BrdU labeling is absent from the RGC layer (indicated by arrowheads). The conus papillaris [large arrows in (a,b)] contains BrdU-labeled cells in both controls and after ONS. However, numbers of BrdU-labeled cells are strongly increased following ONS. The optic nerve contains BrdU-labeled cells only after lesion [small arrows in (b); large arrows in (c)]. (d) Phase contrast image of (c). (e,f) Wholemount BrdU-labeled preparation of a retina, 6 weeks after ONS. Numerous BrdU-labeled cells are visible in the conus papillaris (e), but none are found near the margin of the same retina (f). Scale bar: $200 \mu \mathrm{m}$. 

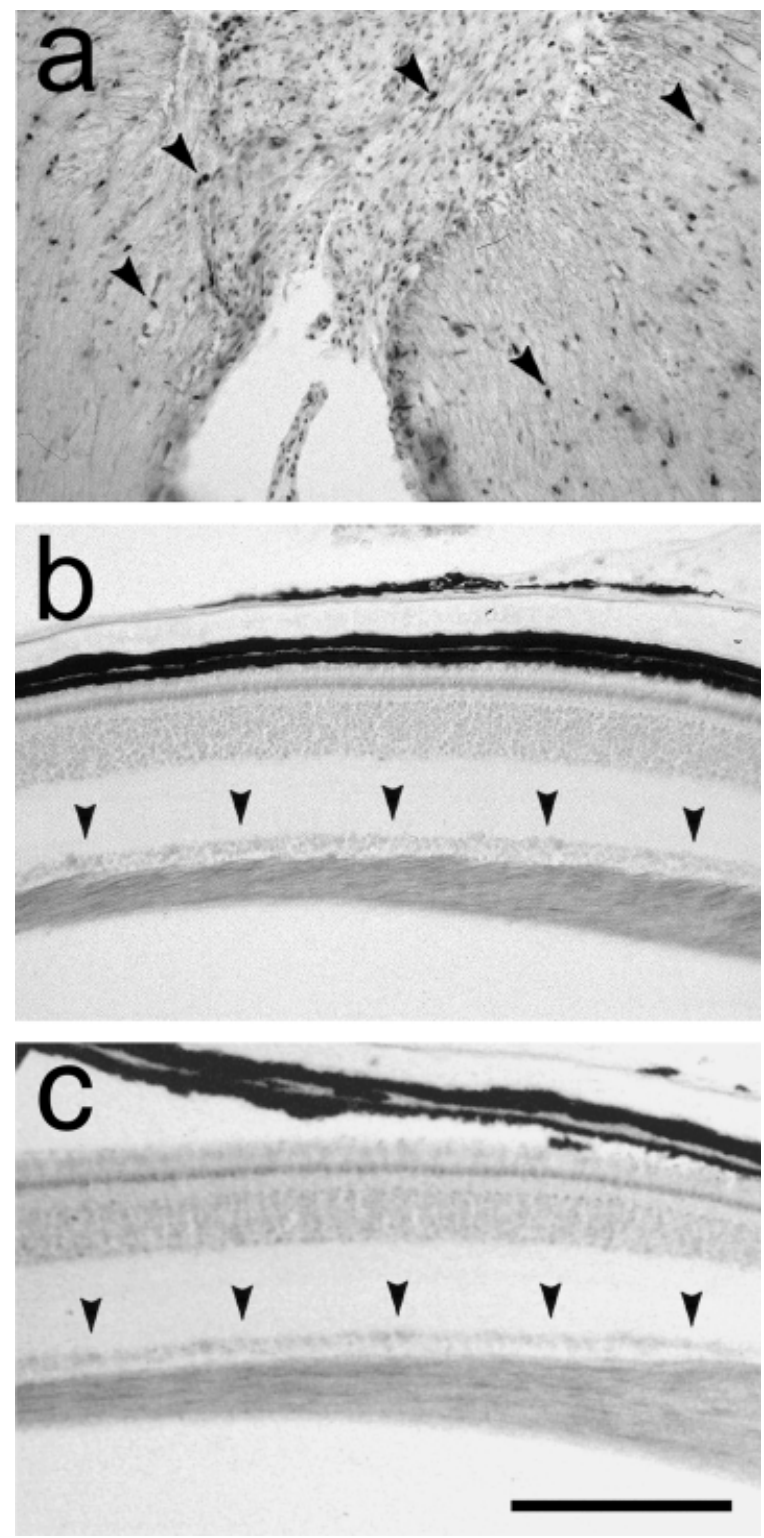

Figure 7 Anti-PCNA-labeled sections of the lizard retina and optic nerve. Weak anti-PCNA-labeling was observed in the RGC layers (indicated by arrowheads) in cross-sections of both control (b) and axon-regenerating retinas (c). However, this did not resemble the PCNA staining seen in proliferating cells (marked by arrowheads) in a longitudinal section of the transection site in the optic nerve (a). Sections are counterstained with antibodies to neurofilaments. Scale bar: $200 \mu \mathrm{m}$.

dragon, Ctenophorus ornatus. While their study was limited to the intact lizard visual system, we extended these findings to the regenerative process and showed that no RGCs arise from possibly resident stem cells as a reaction to optic nerve injury. The fact that we could not detect any newly generated ganglion cells in the adult lizard retina, either in unlesioned controls or following ONS, demonstrates again, and in accordance with a previous report by Beazley et al. (1998), that the ability of CNS neurons to regenerate their axons is not causally linked to the continuous production of neurons in that particular part of the nervous system.

Major differences between these species, however, are evident with respect to the time course of RGC axon regrowth. RGC axons in $C$. ornatus appear to regenerate at a rate similar to that seen in fish or amphibians (Murray, 1976; Humphrey, 1988). In contrast, RGCs in G. galloti-as observed in our HRP tracing experiments-appear to regenerate over a period of at least 9 months after ONS. Judged by the duration of increased C-JUN expression, RGCs in $G$. galloti also remain reactive for much longer periods of time than RGCs in other regenerating systems, where C-JUN becomes down-regulated from about 30 days after axotomy (Herdegen et al., 1993). The prolonged up-regulation of C-JUN expression in G. galloti appears to be concomitant with an extended period during which the axotomized RGCs are capable of regrowing axons, as indicated by increased axon outgrowth from retinal explants even several months after ONS. However, increased C-JUN expression occurs in G. galloti RGCs 1 week after lesion, but RGCs appear to be capable of regrowing axons 6 weeks after ONS. Thus, there appears to be no direct correlation between the onset of axon regeneration and expression of C-JUN in RGCs of G. galloti. Indeed, a recent study indicates that C-JUN expression might not necessarily be required for either retinal axon growth or for apoptotic cell death of RGCs (Herzog et al., 1999). Conversely, C-JUN expression alone does not affect axon regeneration (Schaden et al., 1994), yet it is considered a marker for reactive neurons after axotomy and during regeneration.

Remarkably, axotomized RGCs in G. galloti do not seem to be susceptible to apoptotic cell death, as indicated by our TUNEL assays. This stands in marked contrast to the findings in the mammalian retina, where the majority of axotomized RGCs undergo apoptosis within the first 4 weeks (Berkelaar et al., 1994; Bahr, 2000), and also to results obtained by Beazley et al. (1997), who found that in C. ornatus approximately $30 \%$ of RGCs are lost after ONS. It cannot, however, be entirely excluded that a very low rate of apoptosis in RGCs in G. galloti might go undetected by this detection method, as apoptotic cells are cleared from the tissue rapidly. It is presently unknown what prevents the lizard RGCs from apoptotic cell death, but our preliminary results suggest that BCL-2, a protein that protects cells from entering apoptosis, is expressed at a high level in the lizard 

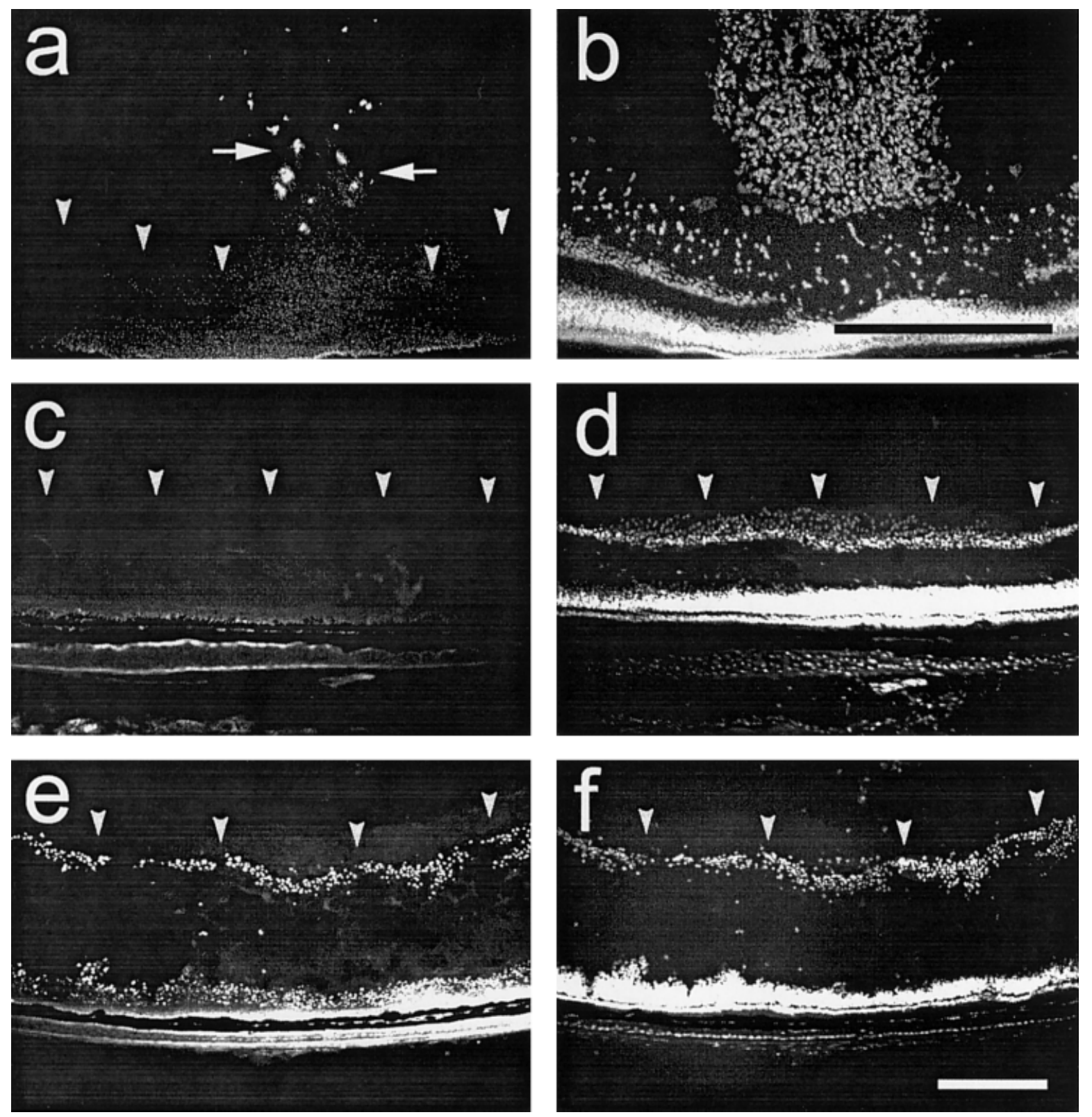

Figure 8 Fluorescent detection of apoptotic cells in the lizard retina after ONS. At no time point after optic nerve lesion [(a), 6 weeks; (c), 6 months] were TUNEL-labeled cells detectable in the RGC layer in cross-sections of retinas (RGC layer marked by arrowheads). Apoptotic cells occurred only in the conus papillaris (arrows). However, injection of sodium glutamate into the vitreous induced apoptotic cell death throughout the retina [(e), RGCs marked by arrowheads]. Presence of RGCs is demonstrated by DAPI-counterstaining (b,d,f). Scale bars: $200 \mu \mathrm{m}$.

retina, particularly in the ganglion cell layer. On the other hand, the BAX protein, an antagonist of BCL-2 that has been implicated in apoptotic death of axotomized rat RGCs (Isenmann et al., 1997), was undetectable in the lizard RGCs (unpublished observations).

One prominent feature observed in our anterograde HRP tracing experiments was the frequent occurrence of pathfinding errors during RGC axon regeneration. Moreover, once arrived in their primary target area, lizard RGC axons do not appear to re-establish a correct retinotopic order (Beazley et al., 1997). In order to navigate back and reconnect to the appropriate target structures, growth cones must be able to detect guidance cues in their microenvironment, such as various cell adhesion and recognition proteins, 
ephrins, netrins, and semaphorins (for reviews: Flanagan and Vanderhaeghen, 1998; Van Vactor and Lorenz, 1999; Stuermer and Bastmeyer, 2000). Is has been shown that ephrin A2 is transiently up-regulated in the tectum of goldfish during re-establishment of the orderly retinotectal projection (Rodger et al., 2000). However, it is at present unknown whether these guidance cues are expressed at all in the adult reptilian $\mathrm{CNS}$ - the large-scale pathfinding errors observed along the lizard optic pathway, in particular the failure of restoration of an orderly projection in the optic tectum, might be explained by their absence or reduced expression. This might also account for the fact that regenerating RGC axons in G. galloti are seen throughout the entire depth of the optic tract, as opposed to young RGC axons, for example, in amphibians, which navigate close to the surface of the optic tract. Another possibility is that the regrowing axons do not express the set of receptors required for detection of these guidance cues. This is an intriguing possibility, supported by our previous observation that regenerating RGC axons in G. galloti are apparently insensitive to myelin-associated axon growth inhibitors (Lang et al., 1998). The glial scar that forms at the transection site in the lizard optic nerve also does not appear to form a barrier for the regenerating RGC axons.

Considering our own and the data available in the literature, is possible that different species of reptiles might indeed have different capacities for optic nerve regeneration, reflected by variations in the survival rates of axotomized RGCs and in the time course of axon regeneration. In a vertebrate class as diverse as reptiles, this would not come as a big surprise. However, the physiological reasons for the differences observed by the various researchers remain unclear. Reptiles being poikilothermic animals, it cannot be excluded that lower than optimal ambient temperatures slow down the time course of degenerative and regenerative changes in the affected tissues. In light of the fact that our experimental animals were kept at relatively high temperatures and had free access to overhead infrared radiation, this appears unlikely. There are currently not enough data available to establish whether RGC survival rates or particular time courses of retinal axon regeneration are typical for certain lizard families, or whether there is a link between regenerative capacity and certain neuroanatomical properties, such as those forming the basis for the establishment of the groups of type I (to which the lacertid G. galloti belongs) and type II lizards (a member of which is C. ornatus; Northcutt and Butler, 1974). It is of interest that the low rate of axotomyinduced RGC death and the prolonged time course of
RGC axon regeneration that we observed in G. galloti have also been observed in the viper, Vipera aspis (Rio et al., 1989). While it is difficult at this stage to point out similarities and differences between the various reptilian species that might be relevant to the postaxotomy survival of RGCs and time course of retinal axon regrowth, the divergent results obtained so far highlight the importance of comparative studies in several organisms before generalized conclusions on axon regeneration in the CNS of the different vertebrate classes may be drawn.

We thank L. Ramirez Quintana and Dr. C. Yanes Mendez for their help with optic nerve transections and animal care.

\section{REFERENCES}

Bahr M. 2000. Live or let die-retinal ganglion cell death and survival during development and in the lesioned adult CNS. Trends Neurosci 23:483-490.

Bandtlow C, Zachleder T, Schwab ME. 1990. Oligodendrocytes arrest neurite growth by contact inhibition. J Neurosci 10:3837-3848.

Bandtlow CE, Loschinger J. 1997. Developmental changes in neuronal responsiveness to the CNS myelin-associated neurite growth inhibitor NI-35/250. Eur J Neurosci 9:2743-2752.

Bastmeyer M, Beckmann M, Schwab ME, Stuermer CA. 1991. Growth of regenerating goldfish axons is inhibited by rat oligodendrocytes and CNS myelin but not but not by goldfish optic nerve tract oligodendrocytelike cells and fish CNS myelin. J Neurosci 11:626-640.

Beazley LD, Sheard PW, Tennant M, Starac D, Dunlop SA. 1997. Optic nerve regenerates but does not restore topographic projections in the lizard Ctenophorus ornatus. J Comp Neurol 377:105-120.

Beazley LD, Tennant M, Stewart TM, Anstee SD. 1998. The primary visual system of adult lizards demonstrates that neurogenesis is not obligatorily linked to central nerve regeneration but may be a prerequisite for the restoration of maps in the brain. Vision Res 38:789-793.

Berkelaar M, Clarke DB, Wang YC, Bray GM, Aguayo AJ. 1994. Axotomy results in delayed death and apoptosis of retinal ganglion cells in adult rats. J Neurosci 14:43684374.

Braekevelt CR. 1989. Fine structure of the conus papillaris in the bobtail goanna (Tiliqua rugosa). Histol Histopathol 4:287-293.

Davies SJ, Field PM, Raisman G. 1994. Long interfascicular axon growth from embryonic neurons transplanted into adult myelinated tracts. J Neurosci 14:1596-1612.

Dieterich HJ, Dieterich CE. 1975. [Comparative electron microscopy studies on the pecten oculi in birds and the conus papillaris in reptiles]. Verh Anat Ges 69:635-642.

Dunlop SA, Tran N, Tee LB, Papadimitriou J, Beazley LD. 
2000. Retinal projections throughout optic nerve regeneration in the ornate dragon lizard, Ctenophorus ornatus. J Comp Neurol 416:188-200.

Fawcett JW, Asher RA. 1999. The glial scar and central nervous system repair. Brain Res Bull 49:377-391.

Fawcett JW, Rokos J, Bakst I. 1989. Oligodendrocytes repel axons and cause axonal growth cone collapse. J Cell Sci 92:93-100.

Flanagan JG, Vanderhaeghen P. 1998. The ephrins and Eph receptors in neural development. Annu Rev Neurosci 21:309-345

Herdegen T, Bastmeyer M, Bahr M, Stuermer C, Bravo R, Zimmermann M. 1993. Expression of JUN, KROX, and CREB transcription factors in goldfish and rat retinal ganglion cells following optic nerve lesion is related to axonal sprouting. J Neurobiol 24:528-543.

Herzog KH, Chen SC, Morgan JI. 1999. c-Jun is dispensable for developmental cell death and axogenesis in the retina. J Neurosci 19:4349-4359.

Humphrey MF. 1988. A morphometric study of the retinal ganglion cell response to optic nerve severance in the frog Rana pipiens. J Neurocytol 17:293-304.

Isenmann S, Wahl C, Krajewski S, Reed JC, Bahr M. 1997. Up-regulation of Bax protein in degenerating retinal ganglion cells precedes apoptotic cell death after optic nerve lesion in the rat. Eur J Neurosci 9:1763-1772.

Johns PR, Heacock AM, Agranoff BW. 1978. Neurites in explant cultures of adult goldfish retina derived from ganglion cells. Brain Res 142:531-537.

Lang DM, Monzon-Mayor M, Bandtlow CE, Stuermer CA. 1998. Retinal axon regeneration in the lizard Gallotia galloti in the presence of CNS myelin and oligodendrocytes. Glia 23:61-74.

Lang DM, Rubin BP, Schwab ME, Stuermer CAO. 1995. CNS Myelin and oligodendrocytes of the Xenopus spinal cord-but not optic nerve-possess non-permissive substrate properties for axon growth. J Neurosci 15:99-109.

Mains RE, Patterson PH. 1973. Primary cultures of dissociated sympathetic neurons. III. Changes in metabolism with age in culture. J Cell Biol 59:361-366.

Margotta V, Morelli A, Alfei L. 1999. PCNA positivity in the telencephalic matrix areas in the adult of a lizard, Podarcis sicula. J Hirnforsch 39:271-276.

Mey J, Thanos S. 1991. Ontogenetic changes in the regenerative ability of chick retinal ganglion cells as revealed by organ explants. Cell Tissue Res 264:347-355.

Meyer RL, Sakurai K, Schauwecker E. 1985. Topography of regenerating optic fibres in goldfish traced with local wheat germ injections into retina: evidence for discontin- uous microtopography in the retinotectal projection. J Comp Neurol 239:27-43.

Moorman SJ, Hume RI. 1993. Omega-conotoxin prevents myelin-evoked growth cone collapse in neonatal rat locus coeruleus neurons in vitro. J Neurosci 13:4727-4736.

Murray M. 1976. Regeneration of retinal axons into the goldfish optic tectum. J Comp Neurol 168:175-195.

Northcutt RG, Butler AB. 1974. Evolution of reptilian visual systems: retinal projections in a nocturnal lizard, Gekko gecko (Linnaeus). J Comp Neurol 157:453-465.

Rio JP, Reperant J, Ward R, Peyrichoux J, Vesselkin N. 1989. A preliminary description of the regeneration of optic nerve fibers in a reptile, Vipera aspis. Brain Res 479:151-156.

Rodger J, Bartlett CA, Beazley LD, Dunlop SA. 2000. Transient up-regulation of the rostrocaudal gradient of ephrin A2 in the tectum coincides with reestablishment of orderly projections during optic nerve regeneration in goldfish. Exp Neurol 166:196-200.

Schaden H, Stuermer CA, Bahr M. 1994. GAP-43 immunoreactivity and axon regeneration in retinal ganglion cells of the rat. J Neurobiol 25:1570-1578.

Singman EL, Scalia F. 1991. Quantitative study of the tectally projecting retinal ganglion cells in the adult frog. II. Cell survival and functional recovery after optic nerve transection. J Comp Neurol 307:351-369.

Smalheiser NR, Crain SM, Reid LM. 1984. Laminin as a substrate for retinal axons in vitro. Brain Res 314:136140.

Stuermer CA. 1988a. Trajectories of regenerating retinal axons in the goldfish tectum: I. A comparison of normal and regenerated axons at late regeneration stages. J Comp Neurol 267:55-68.

Stuermer CA. 1988b. Trajectories of regenerating retinal axons in the goldfish tectum: II. Exploratory branches and growth cones on axons at early regeneration stages. J Comp Neurol 267:69-91.

Stuermer CA, Bastmeyer M. 2000. The retinal axon's pathfinding to the optic disk. Prog Neurobiol 62:197-214.

Van Vactor DV, Lorenz LJ. 1999. Neural development: The semantics of axon guidance. Curr Biol 9:R201-204.

Villegas-Perez MP, Vidal-Sanz M, Bray GM, Aguayo AJ. 1988. Influences of peripheral nerve grafts on the survival and regrowth of axotomized retinal ganglion cells in adult rats. J Neurosci 8:265-280.

Wanner M, Lang DM, Bandtlow CE, Schwab ME, Bastmeyer M, Stuermer CA. 1995. Reevaluation of the growthpermissive substrate properties of goldfish optic nerve myelin and myelin proteins. J Neurosci 15:7500-7508. 